\title{
Evaluation of the Collaborative Performance of Green Supply Chain Management in Battery Manufacturing Enterprises -----A Case of China's Electric Bicycle Battery Enterprise
}

\author{
Zhan Gao ${ }^{1,2}$, Jinkai Li ${ }^{3} *$, Xiaotian Wang ${ }^{1}$, Guanyi Zhang ${ }^{1, *}$ \\ ${ }^{1}$ Henan University of Engineering, Zhengzhou, China \\ ${ }^{2}$ South to North Water Diversion and Yellow River Basin Ecological Environment Research Center, \\ HAUE, Zhengzhou, Henan, China \\ ${ }^{3}$ Zhengzhou University, Zhengzhou, China \\ * Corresponding author: Jinkai Li, Guanyi Zhang
}

\begin{abstract}
Applying green supply chain coordination management is an important strategy for battery manufacturing enterprises, which can effectively develope the campaign of "green industrialization" and promote to recycling of resources. Aiming to improve the green supply chain performance well, firstly this paper constructs a collaborative management model to evaluate the performance of battery manufacturing enterprise from the internal and external supply chain, based on the theory of supply chain. After that, this paper makes an empirical analysis on the system efficient and green performance of the enterprises' green supply chain. As TIANNENG is the largest electric bicycle enterprise in China, here we take it as an example. The results show that the overall green performance of China's electric bicycle battery manufacturing enterprises is well, but with obvious fluctuation. The internal green performance is relatively stable, and there needs new power to get improvement; the external green performance fluctuates fiercely. The results also show the battery manufacturing enterprises should improve the level of waste collection and recovery, increase the efficiency of residual heat recovery and utilization, and improve the organization of green supply chain.
\end{abstract}

Keywords: Green supply chain, cooperative management, performance evaluation, battery manufacturing

\section{Introduction}

Battery manufacturing enterprises in China have developed rapidly, which has formed a Pearl River Delta, Yangtze River Delta, Central Plains Economic Zone and Beijing Tianjin Hebei region based battery industry gathering area. Driven by demand, domestic power battery enterprises continue to grow rapidly and expand their capacity in 2017. According to the data of China chemical and physical power industry association, the power battery capacity in 2016 is about $101 \mathrm{GWh}$, and the shipments are only $30 \mathrm{GWh}$. The total capacity of power battery enterprises in 2017 is more than $230 \mathrm{GWh}$, and the oversupply of capacity is serious. The projects about investment expansion and mergers in lithium battery and its upstream material were up to 143 from 2016 to June in 2017. In the background of the reduction of profit space, battery manufacturing enterprises have to improve competitiveness by improving the green efficiency and changing the development mode. The research on battery manufacturing enterprises for foreign scholars mainly concentrates on agility level capacity upgrading [1-4], shareholder performance management [4], environmental technology improvement [5-7] and so on. Domestic scholars have mainly carried out research on battery manufacturing enterprise waste battery recovery path [8,9], technology [10], logistics resource optimization configuration $[11,12]$ and so on. The domestic research on green enterprise efficiency is concentrated in the industry of steel $[13,14]$, coal mine and photovoltaic power generation. The literature provides key factors in the green supply chain of battery manufacturers. According to the characteristics of battery manufacturers, these factors can be divided into internal and external aspects. Coordinating internal and external factors is the key. The research on collaborative management battery needs to be further studied.

ISSN: 0010-8189

(C) CONVERTER 2020

www.converter-magazine.info 
Taking the green supply chain of the battery manufacturing enterprise as the research object, the paper constructs the green supply chain cooperative management model of the battery manufacturing enterprise from the internal and external supply chain of the core enterprise. By setting up the evaluation system and using the method of catastrophe series appraisal, the paper takes TIANNENG as example, and makes an empirical analysis of the collaboration performance of the green supply chain. The TIANNENG is the largest electric bicycle enterprise in China. Through field research, TIANNENG has relatively complete data than other companies. As taking TIANNENG as example, the overall green performance including internal and external supply chain is well, but with obvious fluctuation. The internal green performance is more stable than the external green performance which fluctuates fiercely. Both internal and external green performance need new power to get improvement.

\section{Green Supply Chain Collaborative Management Mode}

The green supply chain management of battery manufacturing enterprises can be divided into two modules: internal supply chain management and external supply chain management.

The internal green supply chain management refers to the management of the flow of goods within the battery manufacturing enterprise. From the purchase of raw materials to the factory, the process of packaging, storage, transportation and recycling is processed into semi finished products through multiple processes.

The external green supply chain management refers to the green industrial chain network formed by the battery manufacturing enterprise, chemical industry, battery manufacturing industry and other related industries from upstream and downstream.

\subsection{Analysis of green supply chain management module in battery manufacturing enterprises}

In this module, the waste produced by each process in the battery production process is collected, sorted and transported directly to the corresponding production processes for recycling and reuse. These processes are mainly wet pretreatment and fire smelting process, recycling and treating waste batteries, reducing heavy metal pollution and increasing the recycling rate of waste batteries.

2.2 Analysis of external green supply chain management module for battery manufacturing enterprises

In this module, the residual heat and surplus energy recovery in the battery production process are mainly involved. The green supply chain, which belongs to the recycling and utilization of metal wastes, includes: blast furnace slag--industry chain of building material and brick making, sulphur--chemical sulphuric acid industry chain, and fly ash -- industrial chain of cement and rail aluminum alloy. The green supply chain, which belongs to the two energy recovery and utilization includes: hot water and steam--industrial chain of residential water use, blast furnace gas and converter gas-- power generation industry chain, and desulphurization lead paste-- sodium sulfate crystal industrial chain.

2.3 The green supply chain collaborative management analysis of battery manufacturing enterprises

The green supply chain collaborative management of battery manufacturing enterprises integrates the internal green supply chain management module with the external green supply chain management module. Collecting, testing and classifying waste and redundant energy generated by battery manufacturing enterprises. The valuable waste recycling will be used in each process of the battery manufacturing, and the valuable two energy sources will be regenerated through the external supply chain network.

\section{Evaluation Method}

3.1 Index system

ISSN: 0010-8189

(C) CONVERTER 2020

www.converter-magazine.info 
The synergy effect means that when the internal and external effects of the supply chain are combined, the overall effect is greater than the sum of the individual applications. The green supply chain effect of battery manufacturing enterprises includes two aspects. One aspect is the evaluation of internal green supply chain effect, which is mainly evaluated from the perspective of internal energy consumption of manufacturing enterprises. By analyzing the energy consumption of natural gas, water, electricity and other aspects, we evaluate the energy efficiency of manufacturing enterprises in the process of production, processing and waste recycling. The other aspect is the evaluation of external green supply chain effect, which is mainly evaluated from the perspective of external waste discharge from manufacturing enterprises. By analyzing the data of atmospheric emissions and water pollution emissions, the recycling efficiency of waste heat and surplus energy in manufacturing process is evaluated. The total index of the evaluation is decomposed in many levels, which is arranged into a hierarchical structure of tree like target, from the evaluation index to the lower index, and gradually decomposed to the lowest layer index. After the evaluation index is determined, the index with the important degree is placed in front of the same attribute and the same level index, and the relatively minor indicators are placed behind. The selection of internal index is considered from the perspective of green supply chain input. And the selection of external index is considered from the perspective of green supply chain output. According to the actual data of TIANNENG, the related evaluation index system of green supply chain management synergy effect of pool manufacturing enterprises is shown in Table 1.

Table 1 Evaluation index system

\begin{tabular}{|c|l|l|}
\hline First level index & \multicolumn{1}{|c|}{ Secondary index } & \multicolumn{1}{c|}{ Three level index } \\
\hline \multirow{4}{*}{ A Total performance } & \multirow{2}{*}{ B1 Internal green performance } & C1 Electricity consumption \\
\cline { 3 - 3 } & & C2 Use of natural gas \\
\cline { 2 - 3 } & \multirow{2}{*}{ B2 External green performance } & C4 Water consumption \\
\cline { 3 - 3 } & & C5 Discharge of water pollutants \\
\hline
\end{tabular}

\subsection{Evaluation method}

In this paper, we use the catastrophe progression method to evaluate the internal and external performance of green supply chain management in battery manufacturing enterprises. The existing methods of evaluating the performance of green supply chain are analytic hierarchy process, factor analysis, fuzzy evaluation and so on. However, some methods are more subjective or too complicated to determine the weight. The main characteristic of the variable series method is that it first decomposes the overall objective of the system. The main characteristic of catastrophe progression method is to decompose the overall objective of the system at different levels. By using the mutation fuzzy membership function, the normalized formula is integrated and quantized. Finally, it is normalized as a parameter to evaluate it. Catastrophe evaluation method does not use weights to index, but it considers the relative importance of each evaluation index, and combines qualitative and quantitative analysis. This method can reduce the interference of subjective factors, and can accurately analyze and evaluate the internal and external collaborative performance of green supply chain.

\subsubsection{Determine the type of catastrophe system at all levels}

There are three types of catastrophe systems involved in multi-objective decision making models. For the cusp catastrophe system, its model is $f(x)=x^{4}+u x^{2}+v x$. For the swallowtail catastrophe system, its model is $f(x)=\frac{1}{5} x^{5}+\frac{1}{3} u x^{3}+\frac{1}{2} v x+w x$. For the butterfly mutation system, its model is $f(x)=\frac{1}{6} x^{6}+\frac{1}{4} u x^{4}+\frac{1}{3} v x^{3}+\frac{1}{2} w x^{2}+t x$.In the above mutation models, $\mathrm{X}$ represents a state variable in the catastrophe system.

ISSN: 0010-8189

www.converter-magazine.info 
$f(x)$ is potential functions for state variables $x . u, v, w, t$ represent the control variable of the state variable. The state variables and control variables of the system potential function are two contradictory aspects. The control variables interact to form a contradiction, and the main control variables are written in the front, and the secondary control variables are written in the back.

If an index can be decomposed into 2 sub indexes, the system can be regarded as a cusp catastrophe system. If an index can be decomposed into 3 sub indexes, the system can be regarded as a dovetail catastrophe system. If an index can be decomposed into 4 sub indexes, the system can be regarded as a butterfly catastrophe system.

\subsubsection{The normalization formula}

The potential function of the set of catastrophic system is $f(x)$. According to catastrophe theory, all critical point sets are used to synthesize balanced surfaces. Its equation is obtained by derivation of the first derivative of $f(x)$, that is $f(x)^{\prime}=0$. Its singularity set is obtained by finding the two order derivative of $f(x)$, that is $f(x)^{\prime \prime}=0$. By removing $x$ from $f(x)^{\prime}=0$ and $f(x)^{\prime \prime}=0$, the bifurcation point equations of the catastrophe system are obtained. The bifurcation point set equation shows that when the control variables satisfy this equation, the system will mutate. For a cusp catastrophe system, the phase space is three-dimensional, and $f(x)^{\prime}=0$ is obtained. That is, the balanced surface $M$ is given by $4 x^{3}+2 u x+v=0$, and the singularity set is a subset of the $M$ satisfying the equation $12 x^{2}+2 u=0 . \mathrm{X}$ is eliminated by two equations, and $8 u^{3}+27 v^{2}=0$. The split point set is found, and its decomposition form is $u=-6 x^{2}, v=8 x^{3}$. The following normalized formula can be obtained as a mutation fuzzy membership function, such as $x_{u}=u^{\frac{1}{2}}, x_{v}=v^{\frac{1}{3}}$. In the same way, the swallowtail catastrophe bifurcation point set equation is obtained. $u=-6 x^{2}, v=8 x^{3}, w=-3 x^{4}$. The normalization formula is $x_{u}=u^{\frac{1}{2}}, x_{v}=v^{\frac{1}{3}}, x_{w}=w^{\frac{1}{4}}$. Butterfly catastrophe bifurcation point set equation is $u=-10 x^{2}, v=20 x^{3}, w=-15 x^{4}, t=4 x^{5}$. The normalization formula is as follows: $x_{u}=u^{\frac{1}{2}}, x_{v}=v^{\frac{1}{3}}, x_{w}=w^{\frac{1}{4}}, x_{t}=t^{\frac{1}{5}}$.

\subsubsection{Comprehensive evaluation by using the normalization formula}

The normalization formula transforms the different qualities of the control variables into the same state, that is to say, the control variables are unified into the qualitative state expressed by the state variables. When the control variable calculates each state variable value by using the normalization formula, the $X$ value calculated by each control variable corresponding to the variable is used in the principle of "large and medium small" or the average value. If the control variables of the system can not be made up to each other, the smallest one in the values corresponding to the control variables, that is $x_{1}, x_{2}, x_{3}, x_{4}$, is the $\mathrm{x}$ value of the whole system, that is, "large and medium". Only in this way can we satisfy the bifurcation set equation and change qualitatively. The average value of the control variables $u, v, w, t$ and the corresponding $x_{1}, x_{2}, x_{3}, x_{4}$ can be obtained when the various control variables of the system can complement each other and make the $\mathrm{X}$ values higher.

\section{Case Analysis}

\subsection{Current situation of green supply chain management in Henan Tian Neng Group}

Tian Neng group (Henan) Energy Technology Co., Ltd. is a wholly owned subsidiary of Tian Neng group. The company mainly manufactures electric bicycles, traction batteries, electric cars, electric tricycles and other batteries. Its production and sales are in the leading position in the same industry throughout the country, covering the main area of North China. As the enterprise attaches great importance to the reuse of resources and the energy saving and emission reduction, the cooperative management system of green supply chain has been set up ISSN: 0010-8189 
gradually, and two aspects are analyzed from the internal and external green supply chain management respectively. The internal green supply chain management of Tian Neng group (Henan) Energy Technology Co., Ltd. is mainly reflected in the innovation of green technology, reducing energy consumption and increasing the comprehensive recovery and utilization rate. The use of easy dismantling or destruction of the link method, standardized components, reduce the battery manufacturing process of natural gas, electricity, water energy input.

The external green supply chain management of Tian Neng group (Henan) Energy Technology Co., Ltd. is based on Henan Tian Neng group. The enterprise is in deep cooperation with the upstream raw materials procurement, transportation, warehousing and other enterprises, as well as the downstream electric bicycle, electric vehicle, golf car industry, solar energy storage battery and other enterprises. The green supply chain management of Tian Neng group mainly displays in two aspects. First, the recycling of the resources. Through the transformation of acid mist recovery system, 74 charging frames are equipped, and 2 sets of chain plate conveyer belt, 12 sets of cold acid system and 3 battery washing dryer are used. The precipitated acid mist is condensed into the acid mist collection reflux, and the acid mist is reduced by reflux to the battery. Second, the advanced waste gas treatment equipment and emission reduction equipment will make effective use of waste gas resources. The technology of "filtration + water spray + high efficiency filter" is adopted to reduce the emission of smoke and dust. Using resin exchange and reverse osmosis membrane technology to improve the recovery rate of reclaimed water. The annual discharge of waste water is reduced by 346 thousand tons, the amount of lead discharged by waste water is reduced by 61.9 kilograms, the amount of exhaust emission is reduced by 69 million 240 thousand cubic meters, and the emission of lead is reduced by 110.78 kilograms.

\subsection{Henan TianNeng group's green supply chain management synergy effect evaluation}

Before the internal and external green supply chain efficiency is evaluated, the raw data need to be processed without quantity. In this paper, the data of Henan Tian Neng group are standardized by $x^{*}=\frac{x-\min }{\max -\min }$. After standardization, the value is between $(0,1)$. Taking Henan TianNeng 2016 data as an example, $c_{1}$ is monthly use of electricity, $c_{2}$ is monthly gas use, $c_{3}$ is monthly water consumption, $c_{4}$ is monthly atmospheric emission, $c_{5}$ is COD emission, and $c_{6}$ is ammonia nitrogen emission. The monthly standardized data and evaluation indexes of Henan TianNeng group are shown in Table 2.

Among them, $c_{1} 、 c_{2}$ and $c_{3}$ constitute the swallowtail catastrophe model. According to the complementary principle, there are: $x_{B_{11}}=\left(x c_{1}^{1 / 2}+x c_{2}^{1 / 3}+x c_{3}^{1 / 4}\right) / 3=0.861, x_{B_{12}}=0.803, x_{B_{13}}=0.842, x_{B_{14}}=0.862, x_{B_{16}}=0.895, x_{B_{17}}=0.898, x_{B_{18}}=0.909$, $x_{B_{19}}=0.893, x_{B_{110}}=0.925, x_{B_{111}}=0.898, x_{B_{112}}=0.949$.

Among them, $c_{4} 、 c_{5}$ and $c_{6}$ constitute the swallowtail catastrophe model. According to the complementary principle, there are: $x_{B_{21}}=\left(x c_{4}^{1 / 2}+x c_{5}^{1 / 3}+x c_{6}^{1 / 4}\right) / 3=0.769, x_{B 22}=0.695, x_{B 23}=0.579, x_{B 24}=0.619, x_{B 25}=0.571, x_{B 26}=0.602, x_{B 27}=0.779$, $x_{B 28}=0.946, x_{B 29}=0.728, x_{B 210}=0.712, x_{B 211}=0.77, x_{B 212}=0.682$.

$B_{1}$ And $B_{2}$ constitute cusp catastrophe models. According to the principle of small size, there are: $x_{A 1}=\min \left\{x B_{1}^{1 / 2}, x B_{2}^{1 / 3}\right\}=\min \left\{0.861^{1 / 2}, 0.769^{1 / 3}\right\}=0.916, x_{A 2}=0.886, x_{A 3}=0.834, x_{A 4}=0.853$, $x_{A 5}=0.829, x_{A 6}=0.844$. The catastrophe progression method can be used to calculate the monthly and external green supply chain management performance of Henan Tian Neng group in 2016. The result is shown in Table 3.

ISSN: 0010-8189

(C) CONVERTER 2020

www.converter-magazine.info 
Table 2 Green supply chain evaluation index and standardized data

\begin{tabular}{|c|c|c|c|c|c|c|}
\hline & \multicolumn{2}{|c|}{ Internal green performance B1 } & \multicolumn{3}{c|}{ External green performance B2 } \\
\hline Month & $\begin{array}{c}\text { Electricity } \\
\text { consumption c1 }\end{array}$ & $\begin{array}{c}\text { Natural } \\
\text { gas c2 }\end{array}$ & $\begin{array}{c}\text { Water } \\
\text { consumption c3 }\end{array}$ & $\begin{array}{c}\text { Lead } \\
\text { emission c4 }\end{array}$ & $\begin{array}{c}\text { COD } \\
\text { emission c5 }\end{array}$ & $\begin{array}{c}\text { Ammonia } \\
\text { nitrogen c6 }\end{array}$ \\
\hline 1 & 0.6284 & 0.6413 & 0.7442 & 0.3270 & 0.3989 & 1.0000 \\
\hline 2 & 0.4316 & 0.4974 & 0.8536 & 0.3059 & 0.2066 & 0.7799 \\
\hline 3 & 0.6078 & 0.6031 & 0.6612 & 0.3270 & 0.1107 & 0.2205 \\
\hline 4 & 0.6681 & 0.5954 & 0.7410 & 0.3270 & 0.0918 & 0.4872 \\
\hline 5 & 0.7059 & 0.7674 & 0.7519 & 0.3270 & 0.1387 & 0.1499 \\
\hline 6 & 0.6178 & 0.4789 & 1.0000 & 0.3270 & 0.1338 & 0.2721 \\
\hline 7 & 0.8444 & 0.5270 & 0.8765 & 1.0000 & 0.2508 & 0.0687 \\
\hline 8 & 0.8871 & 0.6637 & 0.6965 & 1.0000 & 1.0000 & 0.4902 \\
\hline 9 & 0.8871 & 0.6319 & 0.5982 & 1.0000 & 0.1800 & 0.1475 \\
\hline 10 & 0.9132 & 0.7492 & 0.6926 & 0.4255 & 0.1898 & 0.6860 \\
\hline 11 & 1.0000 & 0.7294 & 0.3954 & 0.4255 & 0.3535 & 0.8175 \\
\hline 12 & 0.9218 & 1.0000 & 0.6244 & 0.4255 & 0.2887 & 0.3657 \\
\hline
\end{tabular}

Table 3 Result of performance evaluation

\begin{tabular}{|l|c|c|c|c|c|c|c|c|c|c|c|c|}
\hline \multicolumn{1}{|c|}{ Month } & 1 & 2 & 3 & 4 & 5 & 6 & 7 & 8 & 9 & 10 & 11 & 12 \\
\hline Internal green performance & 0.8613 & 0.8035 & 0.8421 & 0.8622 & 0.8956 & 0.8561 & 0.8981 & 0.9092 & 0.8931 & 0.9254 & 0.8977 & 0.9497 \\
\hline Enternal green performance & 0.7693 & 0.6947 & 0.5791 & 0.6195 & 0.5706 & 0.6018 & 0.7794 & 0.9456 & 0.7281 & 0.7123 & 0.7701 & 0.6821 \\
\hline Green performance & 0.9163 & 0.8856 & 0.8335 & 0.8525 & 0.8294 & 0.8443 & 0.9203 & 0.9535 & 0.8996 & 0.8931 & 0.9188 & 0.8803 \\
\hline
\end{tabular}

4.3 Analysis of performance evaluation results of green supply chain management

Figure 1 shows the changes in the performance of the green supply chain of Henan Tian Neng group in 2016. From the chart, we can see that the green performance of Henan Tian Neng group shows a "V" shape. The total performance in May was the lowest in 0.8294, and the total performance in August was the highest in the year, reaching 0.9535 . The internal performance change was relatively stable. The lowest point of performance appeared in February, reaching 0.8035, and the highest point appeared in December, reaching 0.9497. The external performance change is relatively intense, the lowest value is 0.8294 in May, the highest value is 0.9456 in August.

According to the analysis of different quarters, the first quarter's internal performance first dropped and then increased, external performance and total performance showed a downward trend. In the second quarter, internal performance showed a trend of first rise and then fall, and external performance and total performance showed a "V" shape change trend. In the third quarter, the internal performance, external performance and total performance showed a trend of rising and decreasing, in which the green external performance improved greatly, and reached a decline after the peak of August. In the fourth quarter, the internal performance, external performance and total performance are fluctuating, in which the internal performance and total performance fluctuate slightly, and the external performance fluctuates greatly.

ISSN: 0010-8189 


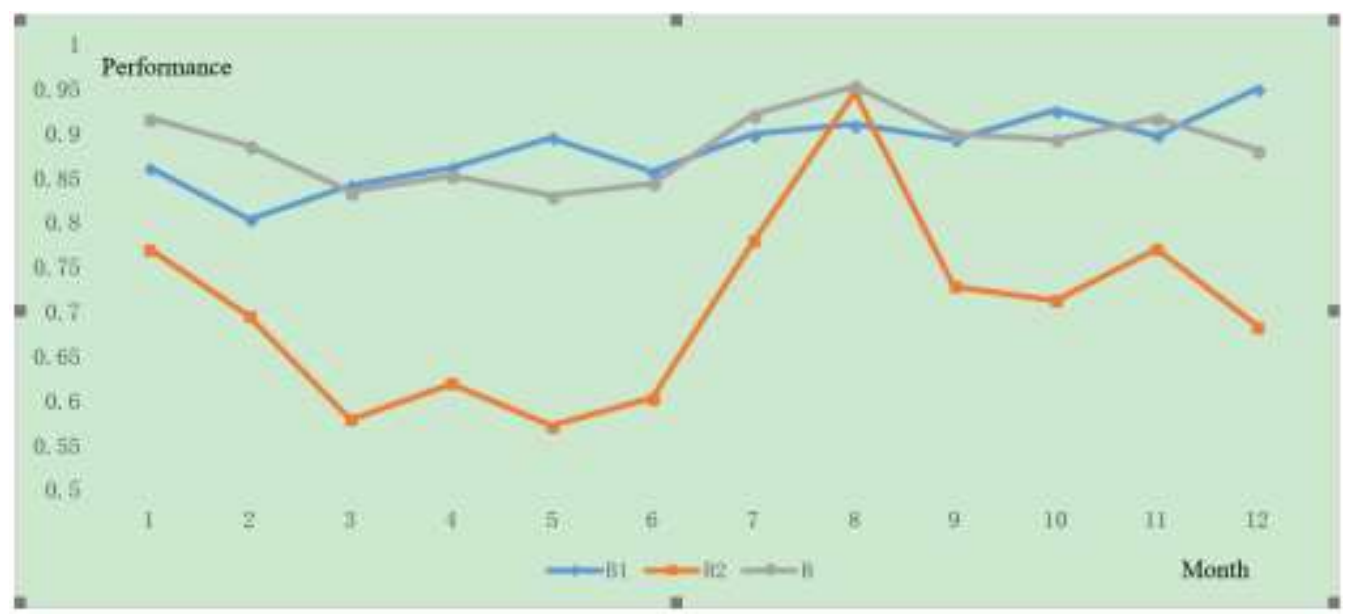

Fig 1: Green supply chain performance evaluation of Henan TianNeng group in 2016

By analyzing the evaluation data of the green supply chain in Henan TianNeng group, we can find that the performance of the internal and external green supply chain has the following characteristics.

Firstly, the performance evaluation of green supply chain is good, but the fluctuation of performance is obvious. The overall performance of Henan TianNeng group in 2016 is 0.885 , and the overall performance of all the months in the year is over 0.8. It shows that the green supply chain management performance of Henan TianNeng group group is good. When the overall performance is good, the monthly fluctuation is obvious, so it is difficult to obtain sustained performance improvement, which indicates that the overall performance improvement is insufficient.

Secondly, internal green performance is relatively stable, and improvement needs new impetus. The performance of internal green performance is relatively stable, the annual average is 0.883 , and each month is more than 0.8 . The internal performance mainly reflects the efficiency of the green logistics in the battery manufacturing enterprises. It shows that the manufacturing enterprises pay attention to the energy input in the selection, processing, packaging, storage and transportation of the battery materials, and make the production of natural gas, water and electric energy in a reasonable proportion, effectively reducing the energy consumption. At present, the improvement of green performance in battery manufacturing enterprises needs to be injected new impetus. The technical innovation of simple specific links can not meet the requirements of significant improvement of performance. It is necessary to optimize the whole chain using systematic thinking from the perspective of internal supply chain.

Thirdly, the sharp change of external green performance is the key to stability and improvement. The green performance of the external supply chain showed a significant fluctuation throughout the year. The fluctuation range was between 0.5706 and 0.9456 , the average value was 0.704 , which was lower than the internal green performance and overall performance. The external green performance reflects the ability of battery manufacturers to be redundant and reclaimed in the manufacturing process, indicating that battery manufacturers are unstable to use existing technologies to improve their external emissions. The battery manufacturing enterprises need to further play the role of the core node enterprises of the external supply chain, integrate and drive the upstream and downstream enterprises to improve the green performance of the external supply chain, and achieve the continuous improvement of the external green performance through the role of integrated integration.

\section{Conclusion}

The collaborative management of green supply chain in battery manufacturing enterprises involves two parts of the management of green supply chain based on the vertical industrial chain and the external green supply chain management, which is based on the coordinated development of the high energy consumption industry group cycle

ISSN: 0010-8189

(C) CONVERTER 2020

www.converter-magazine.info 
economy. The key to the management of green supply chain in the enterprise is the collection, sorting and recycling of waste produced by various processes in the process of battery production. The key to external green supply chain is to recycle waste heat and surplus energy in the process of battery production. The collaborative performance evaluation of green supply chain management of battery manufacturing enterprise relates to the comprehensive evaluation of two aspects of internal and external. The key in the collaborative performance is to balance the relationship between internal and external in the supply chain management.

The application of green supply chain management collaborative performance evaluation model in TianNeng group case shows that the evaluation model can well analyze and reflect the current situation and level change of green supply chain management in battery manufacturing enterprises. The overall performance of green supply chain in China's electric bicycle battery manufacturing enterprises is good, and external performance is the main cause of fluctuations. Electric bicycle battery manufacturers can improve the level of waste collection and recycling, and find new driving force for internal performance improvement. The electric bicycle battery manufacturers can improve the recycling efficiency of surplus energy and obtain the sustainable improvement of external performance. The research results of this paper have a certain theoretical and practical significance for the research of the co management of the green supply chain in the battery manufacturing enterprises and other high-energy consumption industries. Due to the limited data, the index selected need to be enriched. In the further research, more and more variable indexes and cases will be selected to evaluate the synergy effect.

\section{Acknowledgements}

The study was supported by the Fund Project (20FJYB009, D2016029).

\section{References}

[1]Pooja. C.V, Sreenivasa. C.G, "Quantification of agility level using fuzzy logic approach: a case study in a battery manufacturing organization,” in Services \& Operations Management, vol. 26, pp. 428-429, 1997.

[2]Subulan. K, Taşan. A.S, Baykasoğlu. A, “A fuzzy goal programming model to strategic planning problem of a lead/acid battery closed-loop supply chain”, in Manufacturing Systems, vol. 37, pp. 243-264, 2015.

[3]Arunlertaree C, Kaewsomboon. W, Kumsopa. A, et al., "Removal of lead from battery manufacturing wastewater by egg shell”, in Science \& Technology, vol. 29, no. 3, pp. 857-868,2007.

[4]Mohanty. D, Hockaday. E, J. Li, et al., "Effect of electrode manufacturing defects on electrochemical performance of lithium-ion batteries: Cognizance of the battery failure sources", in Power Sources, vol. 312, pp. 70-79, 2016.

[5]Ghanwat. G.H, Patil. A.J, Patil. J.A, et al, "Biochemical effects of lead exposure on oxidative stress and antioxidant status of battery manufacturing workers of Western Maharashtra", India. J Basic Clin Physiol Pharmacol, vol. 27, no. 2, pp. 141-146, 2016.

[6]Kannan. G, Sasikumar. P, Devika. K, "A genetic algorithm approach for solving a closed loop supply chain model: A case of battery recycling" in Applied Mathematical Modelling, vol. 34, no. 3, pp. 655-670, 2010.

[7]Mukherjee. N, Strickland. D, "Analysis and Comparative Study of Different Converter Modes in Modular Second-Life Hybrid Battery Energy Storage Systems”. IEEE Journal of Emerging \& Selected Topics in Power Electronics, vol. 4, no. 2, pp. 547-563, 2017.

[8] J.B. Hui, W.Q. Zheng, J.J. Liu, "Recycling routine and model of spent Zn-MnO2 batteries in China". Battery industry, vol. 15, no. 5, pp. 266-270, 2010.

[9] M.Y. Li, "Research on the construction of reverse logistics network for waste batteries of electric vehicles in uncertain environment.” Donghua University, pp. 22-125, 2014.

[10] J. Cao, "Evaluation of reverse logistics model of waste dry battery based on life cycle assessment." Beijing Jiaotong University, pp. 120-145, 2009.

[11] F. Xie, "Research on reverse logistics model of waste batteries in China." Beijing Business University, pp. 28-45, 2007.

ISSN: 0010-8189

(C) CONVERTER 2020

www.converter-magazine.info 
[12] Y.J. Liu, P. Peng, “Optimization of reverse logistics chain of off vehicle power battery from the perspective of circular economy" in Jiangxi University of science and technology, vol.36, no. 6, pp. 61-65,2015.

[13] F. He, L.Y. Zhu, "Research on green technology efficiency of iron and steel enterprises in China". China's industrial economy, vol. 3, no. 7, pp. 84-98, 2016.

[14] E.S. Qi, S.S. Ma, “Green scale economy of iron and steel industry based on super efficiency DEA." in Industrial engineering, vol. 11 , no. 4 , pp. 1-4,2018. 